\title{
Man impaled on crowbar saved by hospital trauma team
}

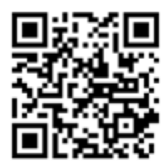

A cool-as-a-cucumber Carltonville mine engineer walked out of hospital 19 days after being impaled from groin to upper back by a 2-metre, $2 \mathrm{~cm}$-thick industrial crowbar, his survival and recovery due to his presence of mind, and world-class trauma surgery. The crowbar pierced three of his body cavities his pelvis, abdomen and chest - missing his heart by $5 \mathrm{~cm}$ and destroying a kidney.

Daniel de Wet slipped while helping with a production breakdown $3.5 \mathrm{~km}$ underground at the goldmine this July. He was using the

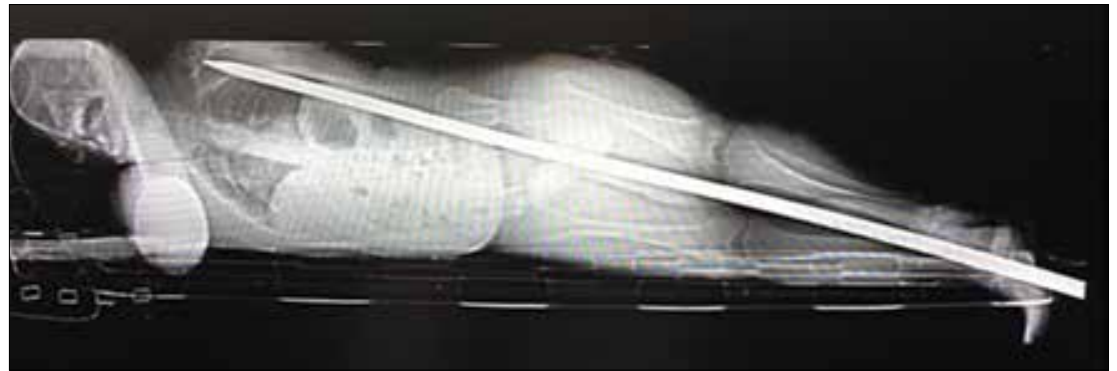

Mining engineer Daniel de Wet's Lodox scan. Note the proximity of the crowbar to the heart.

sharpened metal crowbar, commonly known as a gwala, to stir up mud in an underground dam he and a fellow miner were washing out. He said he tried to stand up on a 
metre-high suction pipe, but slipped. To his utter disbelief, he saw that the gwala had penetrated between his legs, coming out just below his shoulder blade.

'I was talking the whole time, trying to keep the other guys calm - because of the adrenaline rush I had absolutely no pain at first. There was (initially) only one guy with me, he became very scared and didn't know what to do. I told him to calm down and call for help on the two-way radio.' Within minutes, a rigger crew with a first-aid pack and stretcher arrived. 'They didn't know how to put me on the stretcher because of the way the gwala was sticking out of my back. I told the guys: 'Calm down, let's think what to do.'

Accustomed to keeping a cool head in dangerous situations because of being a member of the mine's rescue team and trained to deal with emergencies, De Wet instructed the riggers to perch him on the stretcher in a sitting position - the only way he could be carried 'safely'.

\section{'I was talking the whole time,} trying to keep the other guys calm - because of the adrenaline rush I had absolutely no pain at first. There was (initially) only one guy with me, he became very scared and didn't know what to do. I told him to calm down and call for help on the two-way radio.'

\section{Calm, slow and steady does it}

They carried him through knee-high muddy water for some 40 metres in order to reach a station area, where a cage lift was waiting to hoist them to the surface - no mean feat, as the bottom of the gwala stuck out below De Wet's feet.

'On 34-level sub-shaft, mine paramedics met me and gave me morphine for the pain. I remember nothing further, until I woke up two weeks later in Netcare Milpark Hospital,' said De Wet.

Fortunately he was in highly professional hands, both at the mine and in the hospital. Having been brought up to surface level in three different lifts at a pace that would ensure that he did not suffer adverse decompression effects (more commonly known in deep-water diving as the bends'), he was manoeuvred into a waiting Netcare emergency helicopter, the crowbar tearing the upholstery to accommodate its human 'kebab'. Nearly four hours after the underground accident, the helicopter touched down at Netcare's Milpark Hospital emergency department - one of only two level 1-accredited trauma units in South Africa (Netcare is the only private hospital group in South Africa to have obtained independent classification of its trauma unit, done by the Trauma Society of South Africa using the internationally recognised criteria). The hospital's Trauma Director, Prof. Kenneth Boffard, said he had 'no idea of what was coming [to him], except that it was an impalement?

He began assembling an appropriate operating team and readying the Lodox lowdose, full-body-scan X-ray machine to obtain a precise picture to enable them to plan their surgery. Asked about his initial reaction when confronted by the sight of a person with a metal pole stuck vertically through his body, an unflappable Boffard responded: 'At first it was "good grief", but then I had to apply my mind to the technical problem in order to decide on the best course of treatment.' De Wet was anaesthetised lying on his side. Boffard explained: 'We needed to get him in a position that would enable us to operate, but with the gwala sticking through his back, it was rather awkward. Once he was under, we got some strong paramedics to pull out the gwala by about half a metre so that it was flush with his body. This allowed us to lie him on his back. Fortunately, the gwala had been pressing on the blood vessels and this pressure prevented too much blood loss.' Two surgical teams scrubbed in, one concentrating on the abdomen and one on the chest area.

\section{Staggered operations ensured survival}

'We operated twice on Mr De Wet. In order to safeguard the patient, given the traumatic nature of his injury, our first operation could not last any longer than 60 minutes. During this procedure we did massive damage control in order to stem the bleeding and to contain any form of contamination caused by his injury'

'This is a technical exercise in that one has to know when to stop so that the patient can live to fight another day', explained Boffard. 'During the next, more major procedure [36 hours later when the patient had fully stabilised], extensive repair work was undertaken. This methodology was crucial to full recovery'. De Wet says that his wife was distraught when she heard of the accident, and one of his colleagues immediately drove her to the hospital. 'At the hospital, Prof.

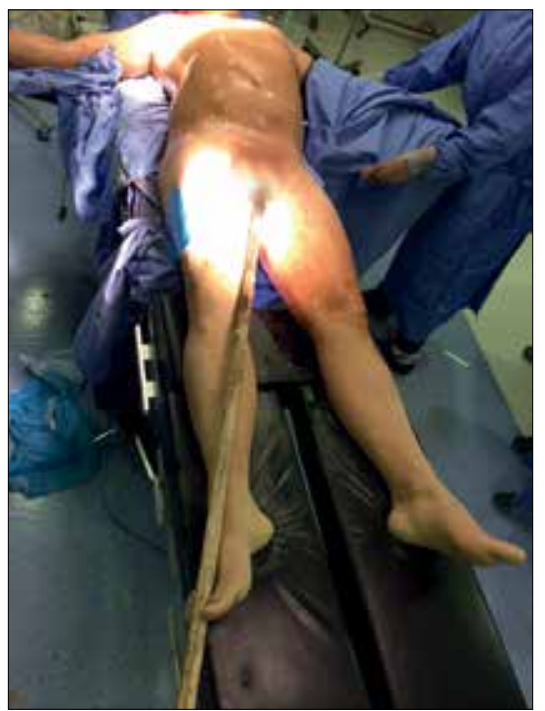

Where the crowbar entered De Wet's body.

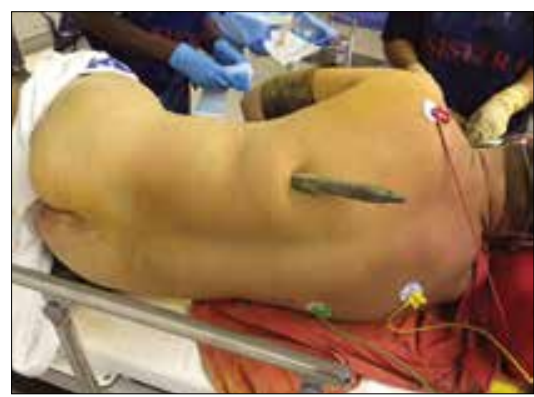

De Wet before his first operation.

Boffard met my wife, and she described his manner as very calm and reassuring. $\mathrm{He}$ reassured her that if I arrived at the hospital alive, I would go home alive.'

Mrs De Wet waited anxiously as the two surgical teams, led by Boffard and Prof. Elias Degiannis, another renowned trauma surgeon at the hospital, worked to save her husband's life. Once the gwala was pulled completely free of De Wet's body, the doctors saw that the impalement had caused significant damage, destroying one kidney and damaging the small bowel and numerous blood vessels. After the initial surgery, Boffard came out of the theatre to speak to Mrs De Wet. 'When Prof. Boffard came out with the gwala in his hand, my wife says she didn't know how to thank him,' De Wet says.

\section{Going beyond the call of duty}

The couple are immensely grateful for what De Wet described as 'absolute caring - Prof. Boffard and his wife also gave my wife a lot of support'.

The survivor's team from the mine came to the hospital to offer support, telling the 
nurses they wanted to pray for him outside the intensive care unit (ICU). The sisters allowed them into the ICU for five minutes, however, and they prayed around their colleague. Says De Wet: 'Even though I was unconscious, they told me later that the tears were rolling down my cheeks when they prayed.'

Once he regained consciousness, he had trouble sleeping and felt anxious. 'One of the nurses was so kind to me, she would talk to me until I fell asleep. The hospital's doctors and nurses went above and beyond the call of duty, not just treating my physical injuries but also showing great compassion for my state of mind and my wife's emotional wellbeing.' Although he had lost a kidney, he made rapid progress and was able to walk after being transferred to the highcare unit, being discharged only 19 days after his dramatic accident. Boffard said the 19-second-duration Lodox scan revealed what a 'miraculous' escape De Wet had, it being 'the longest impalement I've ever dealt with, never mind the survival'. He revealed an added factor that contributed to his patient's recovery: De Wet is a seven-time Comrades Marathon athlete and was in superb physical shape.

He has since returned to active duty at the mine and continues to serve on its rescue team. 'Everyone thought I would resign from mine rescue, but I won't. I have already attended to three fires underground since the accident,' De Wet says.

His employers have had the gwala chromed and mounted on a stone with a bible verse on it, and De Wet plans to donate it to Netcare Milpark Hospital. 'What I have learnt from this whole experience is: "You must believe in miracles every day."'

Boffard said that everything happened according to the textbook. 'We were well prepared to deal with the incoming patient, the mine recovery team were excellent, and Mr De Wet had the benefit of being treated at a world class, level-one trauma unit.

No doubt the patient's level-headedness was another strong contributing factor.

Boffard, Emeritus Professor of Surgery at the University of the Witwatersrand and President Elect of the elite 60-member International Surgery Group, said that the most common impalements he and his local colleagues dealt with were 'front-to-back', usually caused by someone intending grievous bodily harm, burglars jumping out of buildings onto fences or poles (mostly vertical), and motorcyclists flung off their seats in accidents (normally confined to the chest cavity).

\section{Chris Bateman}

chrisb@hmpg.co.za

$S$ Afr Med J 2015;105(7):802-804.

DOI:10.7196/SAMJnew.8603 